ЭКОНОМИЧЕСКИЕ ОСНОВЫ ФУНКЦИОНИРОВАНИЯ РЫНКА ЗЕМЛИ

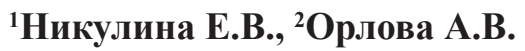 \\ ${ }^{\prime}$ Областное ГАОУ ДПО «Белгородский институт развития образования», \\ Белгород, e-mail: nikulina.2012s@gmail.com; \\ ${ }^{2}$ АНО ВО «Белгородский университет кооперачии, экономики и права», \\ Белгород, e-mail: nikulina_31@mail.ru
}

\begin{abstract}
Эффективное формирование и использование рынка земли определяет экономическое положение страны, что характеризует актуальность исследования. Использовались общенаучные методы, экономико-статистических методы: методы анализа, сравнения, динамики. В статье раскрыты концептуальные положения ренты, рассмотрена зависимость цены земли от меняющихся факторов рынка, изучены формы земельной ренты, их различия и условия. Охарактеризованы подходы, определяющие содержание, механизмы и роль рентных отношений, а также причины образования монопольной ренты. Доказано эволюционное развитие ренты как экономической категории. Проанализированы концептуальные основы рентных отношений: содержание, принципы, значение в экономике и их теории возникновения (классическая, неоклассическая и институциональная). Российский рынок земли представлен в количественном и качественном выражении. Для развития рынка земли в Российской Федерации как объекта хозяйственных и рыночных отношений представлены статистические данные распределения земельного фонда по видовым характеристикам: категориям, формам собственности. Предложены приоритетные направления совершенствования рынка земли и направления государственной политики развития земельного рынка: развитие рыночной доли земли, в том числе в сочетании со смежными свойствами; создание инфраструктуры земельного рынка; информационная поддержка рынка земли.
\end{abstract}

Ключевые слова: экономика, земля, рынок земли, рента, земельные отношения, категории земли, формы собственности земли

\title{
ECONOMIC BASIS OF LAND MARKET FUNCTIONING
}

${ }^{1}$ Nikulina E.V., ${ }^{2}$ Orlova A.V.

${ }^{1}$ Belgorod Institute of Education Development,Belgorod, e-mail: nikulina.2012s@gmail.com; ${ }^{2}$ Belgorod University of Cooperation, Economics and Law, Belgorod, e-mail: nikulina_31@mail.ru

The effective formation and use of the land market determines the economic situation of the country, which characterizes the relevance of the study. General scientific methods, economic and statistical methods were used: methods of analysis, comparison, dynamics. The article reveals the conceptual provisions of rent, considers the dependence of the price of land on changing market factors, studies the forms of land rent, their differences and conditions. The approaches that determine the content, mechanisms and role of rental relations, as well as the reasons for the formation of monopoly rent are characterized. The evolutionary development of rent as an economic category has been proved. The conceptual foundations of rental relations are analyzed: content, principles, significance in economics and their theory of origin (classical, neoclassical and institutional). The Russian land market is presented in quantitative and qualitative terms. For the development of the land market in the Russian Federation as an object of economic and market relations, statistical data on the distribution of the land fund by specific characteristics: categories, forms of ownership are presented. The priority directions for improving the land market and the directions of the state policy for the development of the land market are proposed: the development of the market share of land, including in combination with related properties; creation of land market infrastructure; information support of the land market.

Keywords: economy, land, land market, rent, land relations, land categories, land ownership

Земля, при любом устройстве общества, среди всех видов богатств занимает главное место, являясь объектом экономических и рыночных отношений. Она выполняет важнейшую роль не только в деятельности людей, касающейся хозяйственной системы, но и в их жизни в целом, что обуславливает актуальность исследования. Рынок земли практически во всех экономически развитых странах затрагивает значимые аспекты: экологический (в качестве природного объекта), социальный (условие жизни людей), политический (как территория государства или субъекта федерации).
Цель исследования - определить особенности формирования и функционирования рынка земли Российской Федерации, связанные с его факторным доходным источником, составом и структурой.

\section{Материалы и методы исследования}

Аналитическая часть темы исследования построена на основе показателей Федеральной службы государственной статистики и Федеральной кадастровой палаты федеральной службы государственной регистрации, кадастра и картографии, общенаучные методы, экономико-статистиче- 
ские методы: методы анализа, сравнения, динамики.

\section{Результаты исследования и их обсуждение}

Рынок земли является источником бюджетных доходов во всех государствах. Доход фактора производства, предложение на рынке, которого абсолютно эластично, называется рентой $[1,2]$.

Рента - это особы вид относительно стабильного дохода, формирование и получение, несвязанного с предпринимательством, несмотря на то что это особый тип отношений с недвижимостью по отношению к собственности.

Особым видом ренты является аренда земли, связанная с сельскохозяйственными угодьями. Аренда земли - это плата потребителя за пользование землей собственнику, что в определяемой путем разности добавленной стоимости и средней прибыли.

Цена земли в качестве фактора производства зависит от рыночного спроса и рыночного предложения. Отличие заключается в том, что предложение на рынке земли имеет ограничительно свойство, соответственно, повышение арендой платы и цены не влияет на возможность быстро его увеличить. В итоге предложение земли по эластичности равно нулю на основе долгосрочной аренды и увеличивается путем инвестирования в структурные, экономические и технические меры по улучшению гидрологии, почв и климатических условий.

В современной рыночной системе выделяют две основные формы ренты земли: дифференциальная земельная рента и абсолютная земельная рента.

С количественной точки зрения дифференциальная рента представляет собой разницу между общественной ценой на сельскохозяйственные продукты, которая определяется условиями производства на более бедных территориях, и индивидуальной ценой производства продукции на более плодородных территориях [3].

Монополия на землю как объект экономики является причиной дифференциальной ренты.

Вне зависимости от географического положения отдельных участков земли или ее урожайности абсолютная рента получается владельцами только в качестве вознаграждения за приобретение прав на землю.

В качестве монополии частной собственности на землю абсолютная земельная рента рассчитывается исходя из прибавочной стоимости и средней прибылью (разница между рыночной стоимостью сельско- хозяйственной продукции и общественной ценой производства).

Абсолютная и дифференциальная рента являются двумя основными формами ренты. Кроме них выделяют еще и монопольную ренту. В системе аграрных отношений она занимает особое место.

Причиной еe возникновения служит высокая монопольная цена, которая превышает стоимость продукции - чаще всего на те продукты сельского хозяйства, выработка которых из-за специфических условий произрастания (особенности климата, состав почвы) отстает от общественного спроса (в качестве таких продуктов могут выступать экзотические фрукты). Сверхприбыль, которая образуется за счет потребителя (разность между стоимостью и монопольной ценой продукта) присваивается владельцем земли, на которой выращивается особенный продукт, в форме монопольной ренты.

Дифференциальная, абсолютная и монопольная формы ренты имеют место не только в сельском хозяйстве, но и в добывающей промышленности, а также на строительных участках земли. Они образуются как и в земледелии.

В рыночной экономике земля выступает объектом купли-продажи. Цены на землю, как правило, возрастают по мере роста арендной платы за землю и падения процентных ставок. Инфляционные процессы также влияют на цену земли, поскольку земля - надежный инструмент для вложения денег. Спрос на землю резко вырастет вместе с инфляцией. Помимо этого, стоимости земли значительно возрастает в ходе произведенных операций по повышению ее качества.

Склонность к сокращению предложения земли типична для современных меняющихся условий. Неуклонно растет урбанизация, расширяется использование земли добывающей и строительной промышленностями. По этой причине государство во многих странах национализирует часть земли (покупка у владельцев), создает национальные заповедники, парки, в которых природная среда остается нетронутой по экологическим причинам. Спрос на землю продолжает расти благодаря крупным агрокомпаниям, стремящимся выходить на новые рынки путем расширения сферы своей деятельности. Инициатива исходит от тех покупателей, которые занимаются постройкой зданий за пределами городской черты, и используют землю для иных целей, не связанных с сельским хозяйством.

Вопрос земельной ренты был всегда актуален, что привлекало внимание специ- 
алистов, исследователей. Несмотря на непрекращающееся изучение особенностей земельной ренты, они еще не достигли единого мнения в вопросе о том, чем же она является. В каждой экономической формации, на любой ступени своего развития, люди пытаются дать логичное, структурированное объяснение понятию земельной ренты. Но полученный на сегодняшний день опыт демонстрирует, что эти объяснения чаще всего являлись односторонними, принимали во внимание только одни факторы, не учитывая другие, и всех нюансов земельной ренты не разъясняли (табл. 1).

Таким образом, в экономической теории сформировались концептуальные основы рентных отношений: классическая, неоклассическая и институциональная школы.

Представители классической экономической школы ренту трактуют в узкой интерпретации рентного дохода и анализируют ее путем естественной («дефицитной») ренты. Рента, в контексте теории ценности труда, это один из видов прибавочной стоимости, которая в капиталистической рыночной экономике превышает среднюю прибыль по отрасли. В такой ситуации источником дохода выступает работа сотрудника [4].

Неоклассический подход ренты трактует ее как чрезмерный доход от использования денежных средств (а не только земли). Данная экономическая школа позволяет интерпретировать часть дохода как «финансо- вую ренту», (определяемую разницей фактической стоимостью финансового ресурса и его минимальной стоимостью) [4].

Сторонники институционального подхода акцентируют внимание на поведении, ориентированном на ренту, как специфическом проявлении аренды в современной экономике [5].

В свете нынешнего экономического климата и уровня развития земельных отношения, следует применять широкое толкование понятия рынка земли. Принимая во внимание концепцию коммерциализации в контексте рынка земли, система экономических отношений определяет свободную продажу и права на землю, включая следующие факторы: земля, спрос, предложение, цена, инфраструктура, государственный контроль или национальные контракты [6].

К земельным отношениям относятся: земля как природный ресурс, участки земли, части участков. Состав земель по российскому законодательству [7] включает в себя: земли сельскохозяйственного назначения; земли поселений; земли промышленности, энергетики, транспорта, связи, радиовещания, телевидения, информатики, земли для обеспечения космической деятельности, земли обороны, безопасности и земли иного специального назначения; земли особо охраняемых территорий и объектов; земли лесного фонда; земли водного фонда; земли запаса (табл. 2).

Эволюция взглядов на теорию ренты

Таблица 1

\begin{tabular}{|c|c|c|}
\hline Школа & Представители & Основные положения \\
\hline $\begin{array}{l}\text { Классическая школа по- } \\
\text { литической экономии }\end{array}$ & $\begin{array}{l}\text { Уильям Пети, } \\
\text { Франсуа Кенэ, } \\
\text { Адам Смит, } \\
\text { Давид Риккардо }\end{array}$ & $\begin{array}{l}\text { Теория ренты возникла ввиду ведущей роли сельскохо- } \\
\text { зяйственной отрасли в экономике доиндустриального } \\
\text { общества. С одной стороны, рента возникает в результа- } \\
\text { те влияния на спрос на продукты питания в первичном } \\
\text { секторе, а с другой, из-за различий в условиях производ- } \\
\text { ства, связанных с удаленностью земли от рынка сбыта } \\
\text { и разнообразием урожайности почв }\end{array}$ \\
\hline Марксистская школа & $\begin{array}{l}\text { Карл Маркс, } \\
\text { Владимир Ленин, } \\
\text { Николай Бухарин }\end{array}$ & $\begin{array}{l}\text { В признании «абсолютной» ренты огромную роль сы- } \\
\text { грал Карл Маркс. Под «абсолютной» рентой понимается } \\
\text { рента с худших земель. Согласно утверждениям К. Марк- } \\
\text { са, помимо дифференциальной ренты, существует аб- } \\
\text { солютная рента ввиду права собственности на землю, } \\
\text { по большому счету представляющей монополию }\end{array}$ \\
\hline $\begin{array}{l}\text { Неоклассики и маржи- } \\
\text { налисты }\end{array}$ & $\begin{array}{l}\text { Маршалл Альфред, } \\
\text { Милль Джон Стю- } \\
\text { арт, Кларк, Джон } \\
\text { Бейтс, } \\
\text { Карл Менгер }\end{array}$ & $\begin{array}{l}\text { У представителей неоклассики сформировалась своя } \\
\text { точка зрения. Она закачается в том, что неоклассический } \\
\text { подход к природе обмена основан не на теории стоимости } \\
\text { труда, а на принципах ценности и уникальности. В разных } \\
\text { моделях экономического поведения субъектов выдвига- } \\
\text { ется предположение, что субъекты получают некоторую } \\
\text { форму дохода: «доход, получаемый от потребления ресур- } \\
\text { сов за минусом части, соответствующей доходу от их наи- } \\
\text { лучшего многовариантного использования» }\end{array}$ \\
\hline
\end{tabular}


Таблица 2

Анализ земельного фонда Российской Федерации по категориям за 2018-2020 гг.

\begin{tabular}{|c|c|c|c|c|c|c|c|}
\hline \multirow[t]{2}{*}{$\begin{array}{l}\text { № } \\
\Pi / \Pi\end{array}$} & \multirow[t]{2}{*}{ Наименование показателя } & \multicolumn{3}{|c|}{ Тыс. гектаров } & \multicolumn{3}{|c|}{$\begin{array}{l}\text { В\% от общей } \\
\text { площади }\end{array}$} \\
\hline & & на 01.01.2018 & на 01.01.2019 & на 01.01.2020 & 2018 г. & 2019 г. & 2020 г. \\
\hline 1 & $\begin{array}{l}\text { Земли сельскохозяйственного } \\
\text { назначения }\end{array}$ & 383277,7 & 382509,8 & 381673,0 & 22,38 & 22,34 & 22,27 \\
\hline 2 & $\begin{array}{l}\text { Земли населенных пунктов, } \\
\text { в том числе: }\end{array}$ & 20453,0 & 20501,6 & 20551,70 & 1,19 & 1,19 & 1,21 \\
\hline 2.1 & городских населенных пунктов & 8400,4 & 8403,4 & 8412,7 & 0,49 & 0,49 & 0,5 \\
\hline 2.2 & сельских населенных пунктов & 12052,6 & 12098,2 & 12139,0 & 0,70 & 0,70 & 0,71 \\
\hline 3 & $\begin{array}{l}\text { Земли промышленности и ино- } \\
\text { го специального назначения }\end{array}$ & 17454,9 & 17511,6 & 17614,8 & 1,01 & 1,02 & 1,04 \\
\hline 4 & $\begin{array}{l}\text { Земли особо охраняемых терри- } \\
\text { торий и объектов }\end{array}$ & 47694,2 & 49641,7 & 49646,4 & 2,79 & 2,89 & 2,9 \\
\hline 5 & Земли лесного фонда & 1126288,6 & 1125786,2 & 1126643,0 & 65,77 & 65,75 & 65,78 \\
\hline 6 & Земли водного фонда & 28069,9 & 28070,0 & 28069,4 & 1,64 & 1,64 & 1,64 \\
\hline 7 & Земли запаса & 89330,8 & 88498,2 & 88320,8 & 5,22 & 5,17 & 5,16 \\
\hline \multicolumn{2}{|c|}{ Итого земель в РФ } & 1712519,1 & 1712519,1 & 1712519,1 & 100 & 100 & 100 \\
\hline
\end{tabular}

Составлена авторами на основе данных www.rosstat.gov.ru - Федеральная служба государственной статистики, www.rosreestr.ru - Федеральная служба государственной регистрации, кадастра и картографии (Росреестр).

Площадь земельного фонда Российской Федерации на 1 января 2020 г. составила 1712,519 млн га (без учета внутренних морских вод и территориального моря), и не изменилась по отношению к 2019 г.

В целом, можно сказать, что структура распределения земель по категориям не претерпела серьезных изменений. Таким образом, доля земель различных категорий в 2018-2020 гг. оставалась стабильной с преобладанием земель лесного фонда и сельскохозяйственного назначения. Однако в течение исследуемого периода сократилось количество земель сельскохозяйственного назначения: в 2018 г. - под сельскохозяйственные нужды использовалось 22,38\% всех земель, или 383,3 млн га, в 2019 г. - 382,5 млн га. $(22,34 \%$ всех земель), а в 2020 г. 381,6 млн га. (22,28\% всех земель). Сокращение посевных площадей в основном связано с выделением земель для промышленного строительства, складских и других целей, из-за чего доля промышленных и иного специального назначения земель повысилась и составила $1,03 \%$ от общей площади на начало 2020 г.

Количество земель населений выросло за счет урбанизации. Рост наблюдается как в сельских, так и городских населенных пунктах, что непрерывно ведет к увеличению земель, задействованных под строительство. Так, в 2018 г. под землями населений было 20,4 млн га, а в 2020 г. $-20,55$ млн га.
Количество земель особо охраняемых территорий увеличивалось с каждым годом и в абсолютном выражении выросло на 1,95 млн га в 2020 г. по сравнению c 2018 г.

К землям особо охраняемых территорий и объектов относятся земли, которые имеют особое природоохранное, научное, историко-культурное, эстетическое, рекреационное, оздоровительное и иное ценное значение.

Несмотря на постоянную вырубку лесов на территории Российской Федерации количество земель лесного фонда на протяжении исследуемого периода осталось практически неизменным. Земли лесного фонда с 2018 г. по 2020 г. остались почти неизменными. Земли лесного фонда имеют наибольшую долю в структуре всех земель. Лесной фонд в 2018 г. занимал 65,77\% всей территории РФ, в 2019 г. наблюдалось уменьшение до $65,55 \%$, а в 2020 г. его доля составила уже $65,78 \%$.

Рост площади лесного фонда благоприятен, так как лес является строительным материалом, лес является местом промыслов: охота, сбор лекарственных растений, грибов и ягод. Леса защищают почву от высыхания, следовательно, спасают от опустынивания. Так же леса очищает воздух от загрязнений.

Водные ресурсы, так же очень важны для населения страны. Ведь именно из водоемов вода поступает в дома. И что бы в стране не было нехватки чистой питьевой воды 
нужно заботиться о землях водного фонда. В России в 2018-2020 г. водой было покрыто $1,64 \%$ всей территории, что составляет 28 млн га.

На протяжении 2018-2020 гг. на 1,0 млн га уменьшилось количество земель запаса. Землями запаса являются земли, находящиеся в государственной и муниципальной собственности и не предоставленные гражданам или юридическим лицам. Таким образом, земли запаса - это неиспользуемые земли. Уменьшение количества связано с их вовлечением в хозяйственный оборот и переходом земель или земельных участков в другие категории земель согласно требованиям лесного, водного и земельного законодательства.

Анализ земельного фонда Российской Федерации за исследуемый период представлен на рисунке.

Структурный анализ земель Российской Федерации по формам собственности не претерпел значительных количественных изменений (табл. 3).

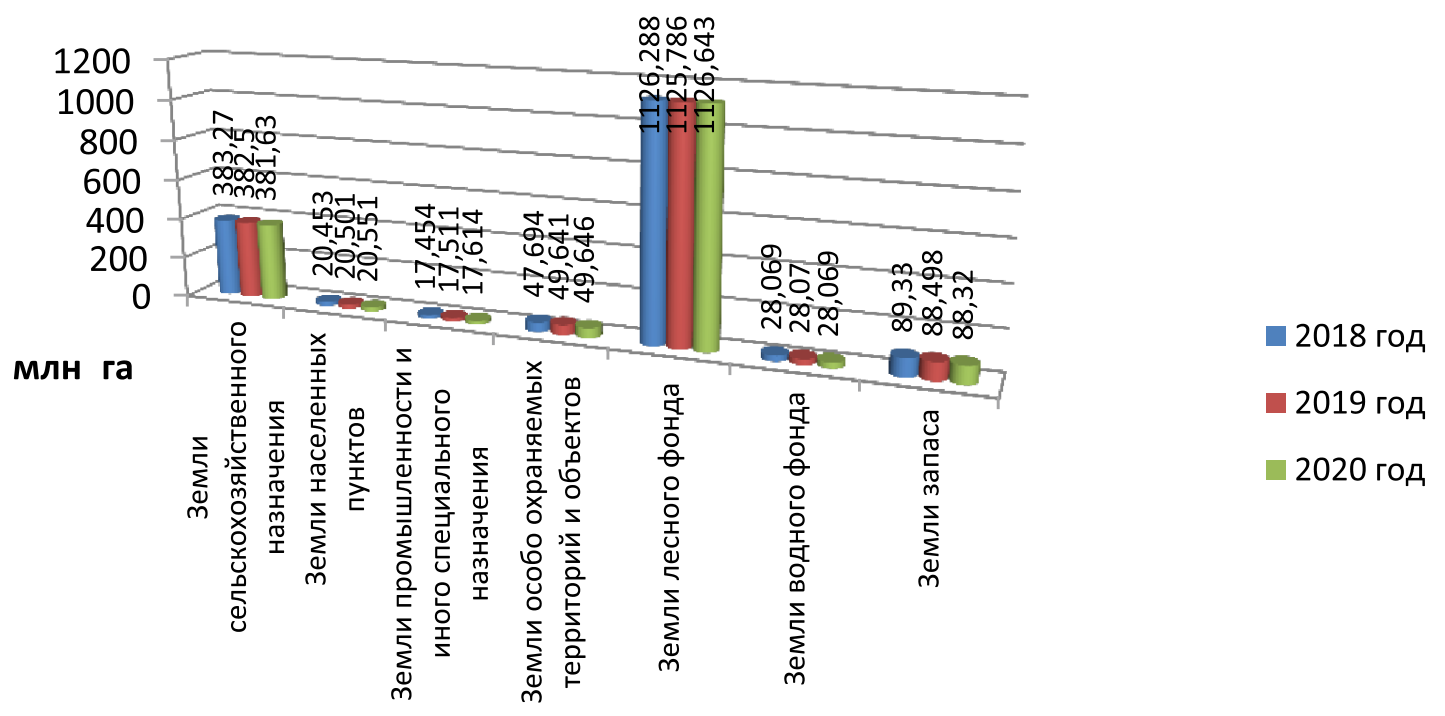

Анализ земельного фонда Российской Федераџии по категориям за 2018-2020 г2.

Анализ земельного фонда Российской Федерации

Таблица 3 по формам собственности в 2018-2020 гг.

\begin{tabular}{|c|c|c|c|c|c|c|c|c|}
\hline \multirow[t]{2}{*}{ Наименование показателя } & \multirow[t]{2}{*}{2018 г. } & \multirow[t]{2}{*}{2019 г. } & \multirow[t]{2}{*}{2020 г. } & \multicolumn{2}{|c|}{$\begin{array}{c}\text { Абсолютное } \\
\text { отклонение }(+,-)\end{array}$} & \multicolumn{3}{|c|}{$\begin{array}{c}\text { Структура } \\
\text { земельного фонда }\end{array}$} \\
\hline & & & & $\begin{array}{l}2019 / \\
2018\end{array}$ & $\begin{array}{l}2020 / \\
2019\end{array}$ & 2018 & 2019 & 2020 \\
\hline Общая площадь, млн га & 1712,52 & 1712,52 & 1712,52 & 0,00 & 0,00 & 100 & 100 & 100 \\
\hline В собственности граждан, млн га & 112,93 & 112,12 & 111,15 & $-0,81$ & $-0,97$ & 6,59 & 6,55 & 6,49 \\
\hline $\begin{array}{l}\text { В собственности юридических лиц, } \\
\text { млн га }\end{array}$ & 20,16 & 20,96 & 21,86 & 0,8 & 0,9 & 1,18 & 1,22 & 1,28 \\
\hline $\begin{array}{l}\text { В государственной и муниципаль- } \\
\text { ной собственности, млн га }\end{array}$ & 1579,43 & 1579,44 & 1579,51 & 0,01 & 0,07 & 92,23 & 92,23 & 92,23 \\
\hline \multicolumn{9}{|l|}{ из них } \\
\hline $\begin{array}{l}\text { В собственности Российской Фе- } \\
\text { дерации }\end{array}$ & 988,72 & 995,29 & 1004,73 & 6,57 & 9,44 & 57,73 & 58,12 & 58,67 \\
\hline $\begin{array}{l}\text { В собственности субъекта Россий- } \\
\text { ской Федерации }\end{array}$ & 20,91 & 22,43 & 21,06 & 1,52 & $-1,37$ & 1,22 & 1,31 & 1,23 \\
\hline В муниципальной собственности & 13,93 & 15,02 & 17,83 & 1,09 & 2,81 & 0,81 & 0,88 & 1,04 \\
\hline
\end{tabular}

Составлена авторами по данным www.rosstat.gov.ru - Федеральная служба государственной статистики, www.rosreestr.ru - Федеральная служба государственной регистрации, кадастра и картографии (Росреестр). 
Большая часть земель за исследуемый период находится во владении государственных и местных властей - 92,23\%. Государству и муниципалитетам принадлежат 92,2\% всех земель Российской Федерации, гражданам - около 6,5\%, а юридическим лицам - 1,3\%. В структурном отношении земель Российской Федерации по формам собственности произошли следующие изменения: уменьшены площади земель, находившихся в собственности граждан (на 0,97 млн га), увеличена собственность юридических лиц (на 0,9 млн га) и государственной и муниципальной собственности (на 0,07 млн га).

\section{Заключение}

Рынок земли имеет специальные признаки. Во-первых, земля - это природное богатство и национальная ценность. Земля подлежит купле-продаже, и от этого зависят экономические отношения, связанные с арендой.

Во-вторых, в зависимости от местонахождения участков, природных и климатических условий земля делится на худшую, среднюю и наилучшую $[8,9]$. Эта классификация основана на естественном плодородии земли, от которого зависит ее продуктивность, которую можно улучшить, инвестируя в нее больше рабочей силы и капитала.

В-третьих, поскольку территория определяется природой, предложение земли характеризуется на экономическом уровне неэластичностью, хотя для отдельно взятого землепользователя ситуация выглядит по-другому: так как он имеет возможность расширить свой доступную площадь земли за счет конкурентов, предложение для него обладает определенной эластичностью. Ограниченность предложения ресурсов земли усугубляется переходом и закреплением ее как частной собственности.

C точки зрения части экономического сектора, рента является доходом такого фактора производства, предложение которого неэластично.

Таким образом, формирование и развитие земельного рынка, выполнение требований структурных и институциональных преобразований в экономике страны должно обеспечиваться путем осуществления взаимозависимых мер государства, которые направлены на преодоление проблем, связанных с функционированием рынка земли [9]. Направления государственной политики развития земельного рынка включают: развитие рыночной доли земли, в том числе в сочетании со смежными свойствами; создание инфраструктуры, информационная поддержка земельного рынка [10].

\section{Список литературы}

1. Нуреев Р.М. Курс микроэкономики: учебник. М.: Норма, 2017. 624 с.

2. Никулина Е.В. Микроэкономика (продвинутый уровень): курс лекций. Белгород: Издательство БУКЭП, 2017.89 c.

3. Джейли Дж.А. Микроэкономика. М.: Высшая Школа Экономики (Государственный Университет), 2015. 736 с.

4. Александрова Е.А. Рентоориентированное поведение в системной теории различных экономических научных школ // Вестник КГУ им. Н.А. Некрасова. 2011. № 4. C. $13-15$.

5. Кураков Л.П., Игнатьев М.В., Тимирясова А.В. Микроэкономика: учебник для вузов. М.: Изд-во ИАЭП, 2017. $353 \mathrm{c.}$

6. Государственный (национальный) доклад о состоянии и использовании земель в Российской Федерации в 2019 году. М.: Росреест, 2020. 206 с.

7. Земельный кодекс Российской Федерации от 25.10.2001 № 136-Ф3 (ред. от 30.04.2021) (с изм. и доп.) [Электронный pecypc]. URL: http://www.consultant.ru/document/cons_doc_ LAW 33773/ (дата обращения: 30.04.2021).

8. Рожков В.Л. Анализ факторов влияния на земельный рынок Российской Федерации // Российское предпринимательство. 2016. Т. 17. № 21. С. 2939-2952.

9. Орлова А.В., Никулина Е.В., Лыщикова Ю.В., Добродомова Т.Н. Алгоритм и инструментарий диагностики капитализации ресурсного потенциала региона // Экономика: вчера, сегодня, завтра. 2016. № 9. С. 160-171.

10. Суворова А.В. Рынок земельных ресурсов: понятия, функции, экономическая сущность // Экономические науки. 2016. № 3. C. 21-22. 